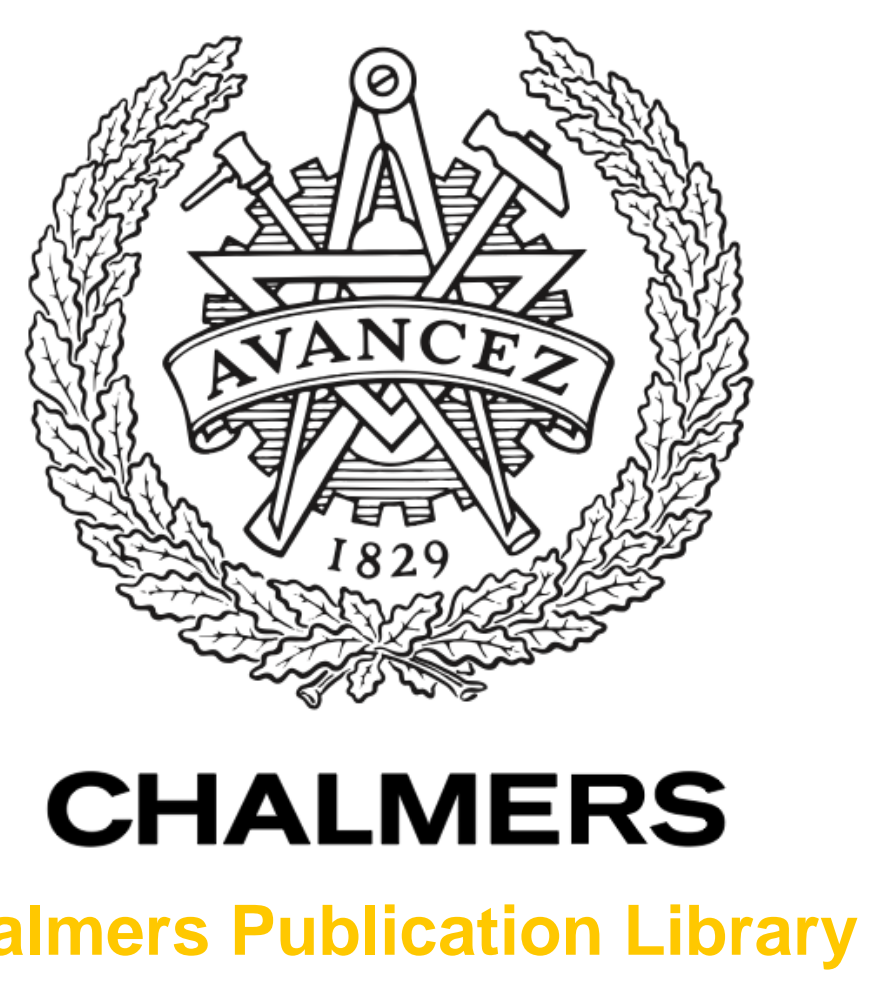

Chalmers Publication Library

\title{
Detection of Thinning and Clear-Cuts using TanDEM-X
}

This document has been downloaded from Chalmers Publication Library (CPL). It is the author's version of a work that was accepted for publication in:

\section{IEEE International Geoscience and Remote Sensing Symposium}

Citation for the published paper:

Persson, H. ; Soja, M. ; Ulander, L. et al. (2015) "Detection of Thinning and Clear-Cuts using TanDEM-X". IEEE International Geoscience and Remote Sensing Symposium

Downloaded from: http://publications.lib.chalmers.se/publication/226252

Notice: Changes introduced as a result of publishing processes such as copy-editing and formatting may not be reflected in this document. For a definitive version of this work, please refer to the published source. Please note that access to the published version might require a subscription. 


\title{
DETECTION OF THINNING AND CLEAR-CUTS USING TANDEM-X DATA
}

\author{
Henrik J. Persson ${ }^{(1)}$, Maciej J. Soja ${ }^{(2)}$, Lars M. H. Ulander ${ }^{(2)}$ and Johan E. S. Fransson $^{(1)}$ \\ (1) Swedish University of Agricultural Sciences (SLU), Umeå, Sweden \\ ${ }^{(2)}$ Chalmers University of Technology, Gothenburg, Sweden
}

\begin{abstract}
Interferometric TanDEM-X data from 2011 and 2014 were used to create biomass maps over the Swedish test site Remningstorp. These maps were used to compute the biomass change for four classes; pre-commercial thinning, thinning, clear-cutting, and untouched forest. Field inventory and ALS data from the corresponding years were used as reference data. The biomass change was compared on 12 subjectively chosen plots with $40 \mathrm{~m}$ radius for each class.

It was found, that pre-commercial thinning was difficult to detect, as the biomass loss was less than the biomass growth during the four vegetation seasons investigated. Thinning could be detected from the biomass change being about zero or slightly negative, while clear-cut plots were obvious to notice, with the biomass withdrawal being several hundreds of tons $\mathrm{ha}^{-1}$. The untouched plots had a biomass growth of about 4 to 6 tons $\mathrm{ha}^{-1}$ year $^{-1}$.

It was concluded, that annual TanDEM-X images can be used to detect also smaller silviculture activities such as thinning, but further research with shorter time periods would be desired.
\end{abstract}

Index Terms - Forestry, biomass, TanDEM-X, change-detection

\section{INTRODUCTION}

Topical data about the forest have become accessible through technical progress within remote sensing and can be used for applications such as forest management planning, climate modeling and detection of illegal deforestation. The use of spaceborne systems simplifies the acquisition of affordable frequent large-area data. Furthermore, when the spaceborne platform is used in combination with synthetic aperture radar (SAR), which is an active microwave sensor, weather- and daylight-independent images can be acquired with pixel resolutions on the order of meters. The TanDEMX (TDM) system from the German Aerospace Center (DLR) offers such images and consists of two, almost identical twin satellites TerraSAR-X (launched in June 2007) and TanDEM-X (launched in June 2010). The images from the two satellites were acquired with spatial baselines of a few hundreds of meters and negligible temporal baselines, which made single-pass interferometric SAR (InSAR) suitable as one processing method to create digital surface models (DSMs). The DSMs can be used in combination with external airborne laser scanning (ALS) high-resolution digital terrain models (DTMs) in order to extract accurate forest related data. Such data can be for example the scattering phase center above ground, which is related to the forest height and volume, canopy structure and possibly also tree species [1]-[3]. The detection of clear-cuts and biomass changes from satellite radar data has been partially studied, but the sensitivity is still uncertain and more study areas are needed [4], [5].

In this paper, the sensitivity of TanDEM-X based interferometry will be evaluated for detection of precommercial thinning, thinning, and clear-cutting. It will be quantified how much forest that has to be removed for the evaluated approach to work properly, i.e. to detect a change.

\section{MATERIALS AND METHODS}

Extensive data sets are available for the hemi-boreal forest in Remningstorp $\left(58^{\circ} \mathrm{N}, 19^{\circ} \mathrm{E}\right)$, Sweden, between 2011 and 2014. After the vegetation season 2010, a systematic inventory with 262 field plots with $10 \mathrm{~m}$ radius, $200 \mathrm{~m}$ apart, was carried out. Trees with diameter at breast height $(\mathrm{DBH}) \geq 0.04 \mathrm{~m}$ were calipered and the height was measured on a sub-sample of about $10 \%$ of the trees. This inventory was repeated in the fall 2014 , with the change that $25 \%$ of the tree heights were now measured. In addition to this, late 2010 and early 2011, 32 field plots with $40 \mathrm{~m}$ radius were inventoried using the same premises. This inventory was repeated in the fall 2014 as well, with clearcut plots replaced and complemented with new ones, giving 40 field plots. Because of the availability of only few deciduous plots at $40 \mathrm{~m}$ radius, these were removed which resulted in 29 employed plots 2011 and 38 for 2014. All following field data sets were therefore valid only for coniferous forest $(>70 \%)$. For all field inventoried plots, above-ground biomass (AGB) were computed species-wise using allometric equations originating from [6], [7] and later updated by [8], where DBH, species and tree height were the independent explanatory variables. Plots located on agricultural land, private gardens and clear-cut forest were

(C) 2015 IEEE. Personal use of this material is permitted. Permission from IEEE must be obtained for all other uses, in any current or future media, including reprinting/republishing this material for advertising or promotional purposes, creating new collective works, for resale or redistribution to servers or lists, or reuse of any copyrighted component of this work in other works. 

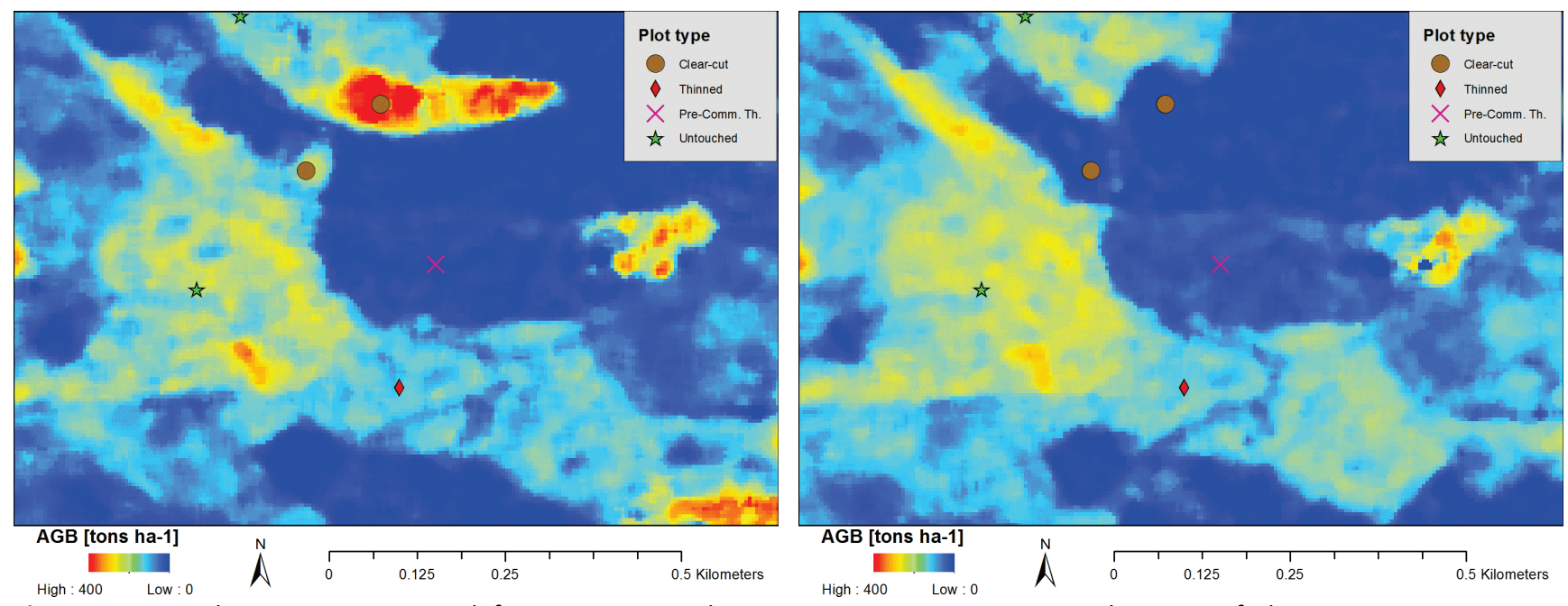

Figure 1. Example on AGB computed from TanDEM-X data at two time points in a sub-region of the Remningstorp test site. The classification symbols are not correctly scaled, but represent circular plots with $40 \mathrm{~m}$ radius. Left: 2011 Right: 2014.

removed, resulting in two hundred twenty six available $10 \mathrm{~m}$ plots from the 2010 inventory and two hundred nineteen $10 \mathrm{~m}$ plots from 2014.

ALS data were collected in the fall 2010 and in the fall 2014 with $>10 \mathrm{~m}^{-2}$ point density. Rasters with $5 \mathrm{~m}$ pixel size were computed containing the percentiles $30,60,95$, and 99 , and the vegetation ratio (defined as the number of 1 st returns above a $1.37 \mathrm{~m}$ threshold divided by the total number of returns).

TanDEM-X data were acquired in strip-map mode 4 June 2011 and 2 August 2014, both with VV polarization and $141 \mathrm{~m}$ across-track baseline (suitable for forest mapping [9]). The images have been processed interferometrically to generate canopy height model (CHM) and coherence maps.

Linear regression models were created, relating ALS data (percentile 99 and vegetation ratio) to the field inventoried AGB, on the more than 200 field plots with 10 $\mathrm{m}$ radius. The regression models were used to create wallto-wall maps of AGB over the entire test site, using the ALS data from respective years. The maps were computed with $17.5 \mathrm{~m}$ pixel size, to correspond approximately to the inventoried area unit $\left(314 \mathrm{~m}^{2}\right.$ vs. $\left.306 \mathrm{~m}^{2}\right)$. The wall-to-wall maps were evaluated against the field inventoried $40 \mathrm{~m}$ plots at respective year. The RMSE was $15.9 \%$ for the 2010 ALS AGB map and $14.6 \%$ for the 2014 ALS AGB map. Corresponding AGB maps were computed for 2011 and 2014 using the TanDEM-X based map data, but these nonlinear regression models were employing the $40 \mathrm{~m}$ field data sets only, as the accuracy has been shown to decrease considerably at $10 \mathrm{~m}$ radius compared to $40 \mathrm{~m}$ radius [10]. The non-linear regression model used for AGB estimation was:

$$
A G B=C \cdot H^{\alpha} \cdot \operatorname{Coh}^{\beta}
$$

where AGB is the above-ground biomass, $C$ a scaling constant, $H$ the interferometric height, $\mathrm{Coh}$ the interferometric coherence, and $\alpha$ and $\beta$ exponent variables to be fitted by the model. Without separate validation data sets, a leave-one-out cross-validation was performed, which resulted in $12.7 \%$ and $12.0 \%$ RMSE for 2011 and 2014, respectively.

The silviculture activities performed from 2011 to 2014 have been put together stand-wise and they were divided into three classes: pre-commercial thinning (lower vegetation removal, often with $\mathrm{DBH}<0.07 \mathrm{~m}$ ), thinning (about $30 \%$ of the basal-area is removed, but letting the mean tree height remain), and clear-cutting (almost all trees removed). A fourth class, untouched forest, was also added (no specific silviculture activities performed, but with natural growth taking place). To get a reasonable basis of data for respective forest silviculture activity, 12 subjective locations where chosen for each class (Figures 1 and 2). The locations were selected relatively even over the test site in coniferous forest $(>50 \%)$, approximately in the stand centers and only in stands having room for an entire $40 \mathrm{~m}$ radius

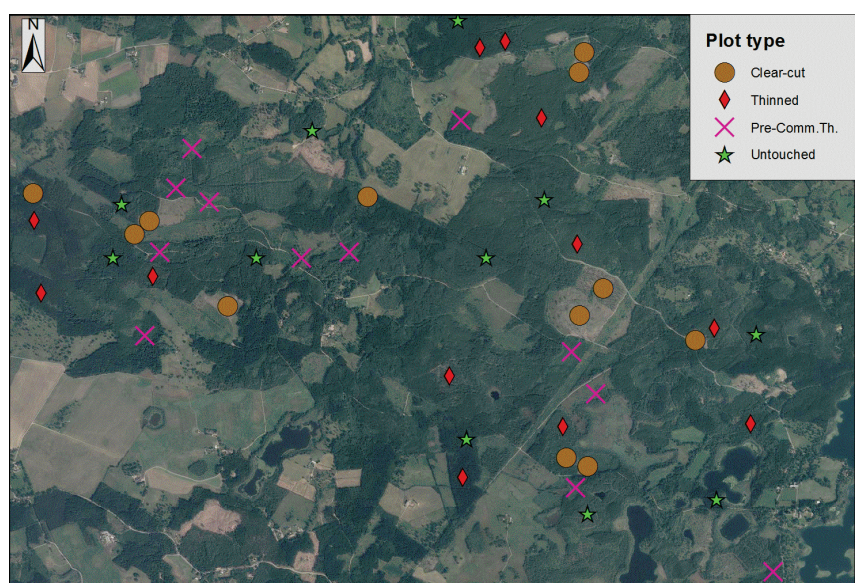

Figure 2. Illustration of the evaluated plot locations for each class at the Remningstorp test site. The classification symbols are not correctly scaled, but represent circular plots with $40 \mathrm{~m}$ radius. 


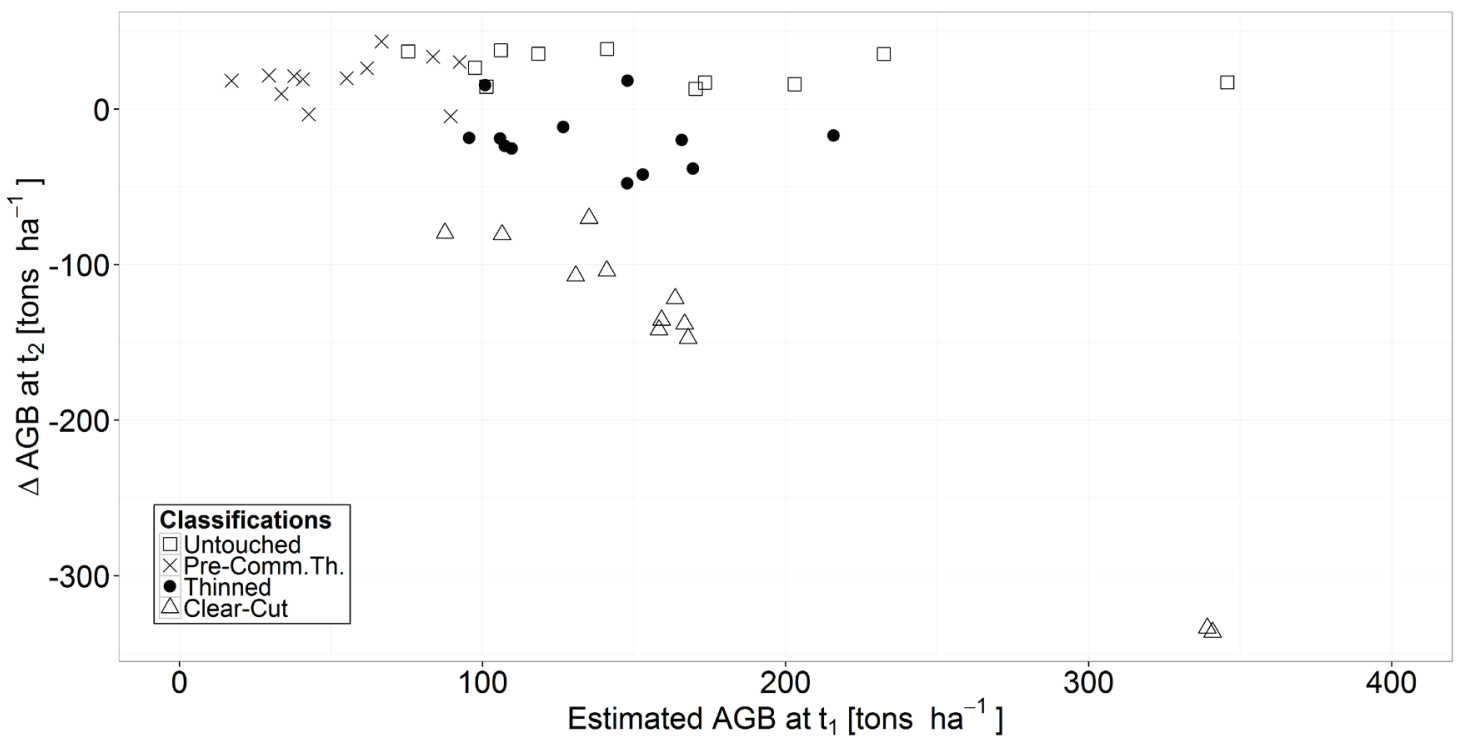

Figure 3. Scatterplot of the estimated change of AGB from ALS data between 2011 and 2014, for four classifications.

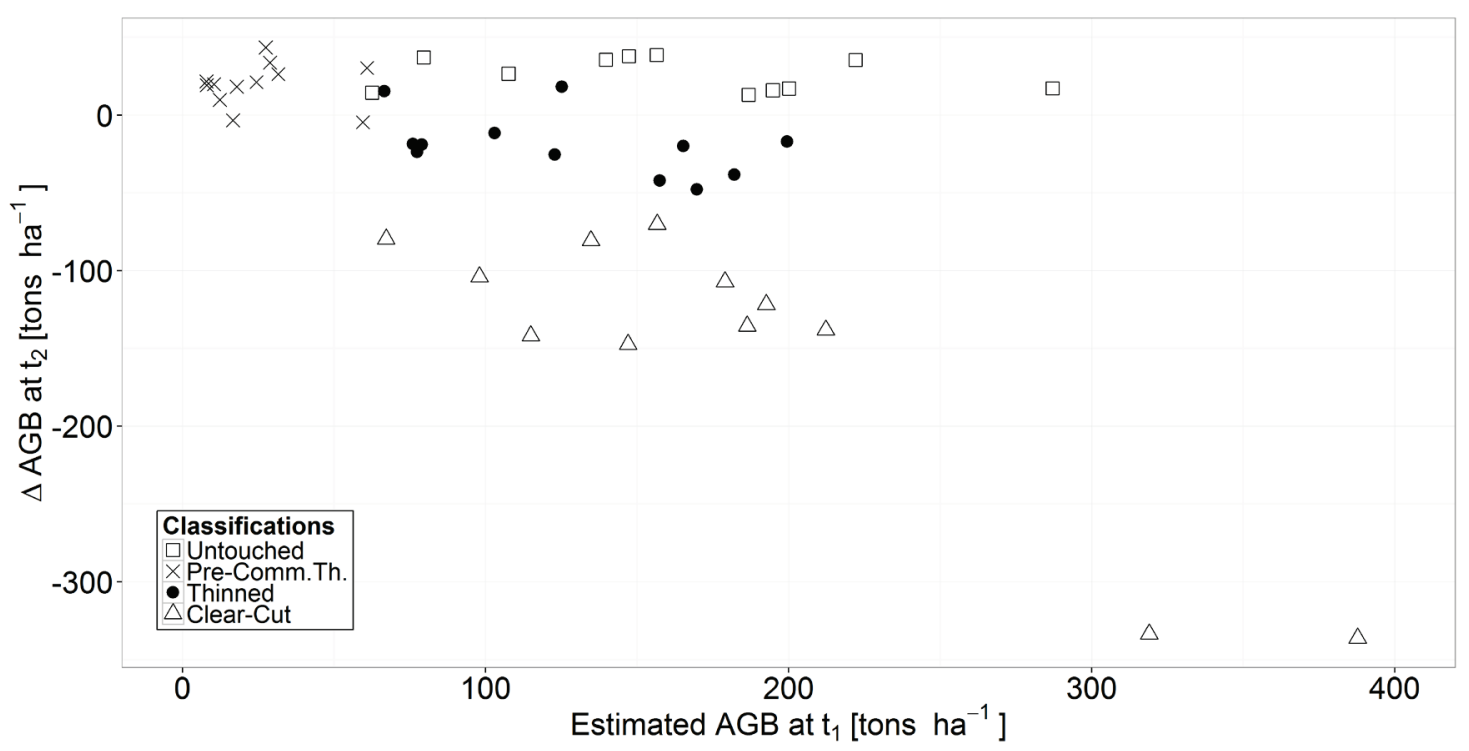

Figure 4. Scatterplot of the estimated change of AGB from TanDEM-X data between 2011 and 2014, for four classifications.

circular plot (Figure 2). For each silviculture activity the AGB change was computed as the difference between the later and the former AGB map, derived from ALS data and TanDEM-X data, respectively. The differences were then averaged for the 12 plots within each class.

\section{RESULTS}

The averaged AGB differences for each class are summarized in Table 1, and the change of AGB at plot-level is presented in the scatterplots Figures 3 and 4 . The range of AGB change was about -5 to 43 tons $\mathrm{ha}^{-1}$ for precommercial thinning, -48 to 20 tons $\mathrm{ha}^{-1}$ for thinning, and -379 to -350 tons $\mathrm{ha}^{-1}$ for clear-cut plots. For the untouched forest plots, an increase (originating in forest growth) of AGB was -9 to 41 tons $\mathrm{ha}^{-1}$. From the scatterplots, trends can be noticed for the different classifications, despite "negative growth" occasionally appears at plot-level. The correspondence between ALS and TanDEM-X based data is high, even though the absolute values differ slightly.

\begin{tabular}{|l|l|l|l|l|}
\hline $\begin{array}{l}\text { Data } \\
\text { source }\end{array}$ & $\begin{array}{l}\text { Untouched } \\
\text { forest }\end{array}$ & $\begin{array}{l}\text { Pre-commercially } \\
\text { thinned }\end{array}$ & Thinned & $\begin{array}{l}\text { Clear- } \\
\text { cut }\end{array}$ \\
\hline ALS & 25.4 & 19.6 & -19.2 & -150 \\
\hline TanDEM-X & 15.5 & 17.8 & 5.58 & -155 \\
\hline
\end{tabular}

Table 1. Average change of AGB in $\left[\right.$ tons ha $\left.{ }^{-1}\right]$ between 2014 and 2011. 


\section{DISCUSSION AND CONCLUSIONS}

For the clear-cut plots, it was clear that the forest was removed and the change was dramatically large both in the ALS data and TanDEM-X data (Table 1). Already for the thinned forest though, the uncertainty started to appear. In the ALS data a smaller negative change of AGB could be seen, but still far from the change in the clear-cut plots, even though roughly $30 \%$ of the AGB had been removed. The thinned and untouched forest plots both showed an increase of the AGB over the almost four vegetation seasons, despite the increase was smaller for the thinned plots compared to the untouched plots in the ALS data. This was an expected result as the removed AGB is likely to be smaller in a thinning than the AGB increase from forest growth during four years. Remningstorp contains well-managed forest and the increase of AGB is roughly 6.4 tons $\mathrm{ha}^{-1}$ year $^{-1}$ (computed from the untouched ALS AGB forest plots as "ground truth"), which means that a thinned plot (assume 200 tons $\mathrm{ha}^{-1}$ ) after one year decreases its AGB with $30 \%$ to 140 tons $\mathrm{ha}^{-1}$, but the following three years the AGB increases to about $80 \%\left(159\right.$ tons $\left.\mathrm{ha}^{-1}\right)$ of the original AGB. Therefore, smaller changes than clear-cuts or thinnings over such a long time-period as four years seem difficult to detect out of only start and end states computed from remotely sensed data. Consequently, a future study should focus on much shorter time intervals in order to show possible detections of forest silviculture activities. This study also shows that the common assumption of a "static" forest state over a couple of year period is likely to deviate substantially in most cases.

\section{ACKNOWLEDGEMENTS}

The authors would like to thank the Swedish National Space Board (SNSB) for the funding, and the German Aerospace Center (DLR) for the TanDEM-X data.

\section{REFERENCES}

[1] J. Praks, O. Antropov, and M. T. Hallikainen, "LIDAR-aided SAR interferometry studies in boreal forest: scattering phase center and extinction coefficient at X-and L-band," IEEE Trans. Geosci. Remote Sens., vol. 50, no. 10, pp. 3831-3843, 2012.

[2] S. Solberg, R. Astrup, J. Breidenbach, B. Nilsen, and D. Weydahl, "Monitoring spruce volume and biomass with InSAR data from TanDEM-X," Remote Sens. Environ., vol. 139, pp. 60-67, Dec. 2013.

[3] M. J. Soja, H. Persson, and L. M. H. Ulander, "Estimation of forest height and canopy density from a single InSAR correlation coefficient," IEEE Geosci. Remote Sens. Lett., vol. 12, no. 3, pp. 646650, 2015.
[4] S. Solberg, E. Næsset, T. Gobakken, and O.-M. Bollandsås, "Forest biomass change estimated from height change in interferometric SAR height models," Carbon Balance Manag., vol. 9, no. 1, p. 5, Sep. 2014.

[5] A. Pantze, M. Santoro, and J. E. S. Fransson, "Change detection of boreal forest using bi-temporal ALOS PALSAR backscatter data," Remote Sens. Environ., vol. 155, pp. 120-128, Dec. 2014.

[6] L. G. Marklund, "Biomass functions for Norway spruce (Picea abies (L.) Karst.) in Sweden," Swedish University of Agricultural Sciences, Umeå, Sweden, 1987.

[7] L. G. Marklund, "Biomassafunktioner för tall, gran och björk i Sverige," Umeå, Sweden, 1988.

[8] H. Petersson, "Biomassafunktioner för trädfaktorer av tall, gran och björk i Sverige," Arbetsrapport 59, 1999, Sveriges Lantbruksuniversitet, 1999.

[9] M. J. Soja and L. M. H. Ulander, "Digital canopy model estimation from TanDEM-X interferometry using high-resolution Lidar DEM," in In Proceedings of IEEE International Geoscience and Remote Sensing Symposium, 2013, pp. 165-168.

[10] H. Persson, "Estimation of Forest Parameters Using 3D Satellite Data," Swedish University of Agricultural Sciences, Doctoral thesis, 2014. 